\title{
WYRAU'HAW: A FESTA DA MENINA-MOÇA DO POVO INDÍGENA TENETEHARA/GUAJAJARA
}

Ana Caroline Amorim Oliveira (1) $\square$

Universidade Federal do Maranhão. Programa de Pós-Graduação em

Cultura e Sociedade I São Luís - MA - Brasil 
Este ensaio fotográfico ilustra a Wyrau'haw, conhecida como Festa da Menina-Moça ou Festa do Moqueado (Figuras 1 a 8). Trata-se de um ritual do povo Tenetehara/ Guajajara, de língua Tupi, localizados na pré-Amazônia maranhense. Esta festa marca a passagem da mulher Tenetehara/Guajajara da infância para a vida adulta. Ela é composta por três momentos: Mandiocaba, ou Festa da Mandiocaba, Caçada e Festa do Moqueado (Gomes 2018). O presente ensaio referese à última etapa desta festa, a Festa do Moqueado, que ocorreu em setembro de 2016, na aldeia Lagoa Quieta, Terra Indígena (TI) Arariboia. Os Tenetehara chamam de Wyrau'haw o momento da passagem e de transformação de menina para a idade adulta. Em português, eles usam a palavra "festa" para se referirem a esse momento de relação entre os vivos e os encantados.

Os Tenetehara conheceram as festas e como realizá-las com os encantados. Esses eventos marcam a comunicação entre o plano empírico e o plano dos encantados. Como afirma Renato Sztutman (1998:124), sobre o sentido que a festa possui entre os Waiãpi, povo Tupi da região amazônica: "É a atividade ritual - a festa - a instância capaz de colocar em prática este processo de transformação, essa incessante necessidade de transpor o plano das relações empíricas à comunicação com outros planos".

\section{REFERÊNCIAS}

Gomes, E. 2018. Os Tenetehara e seus rituais: um estudo etnográfico na Terra Indígena Pindaré. Dissertação de Mestrado, Universidade Estadual da UEMA, Departamento de Cartografia Social, São Luiz.

Sztutman, R. 1998. Cauinagem, uma comunicação embriagada: apontamentos sobre uma festa tipicamente ameríndia. Sexta Feira - Antropologia, Artes e Humanidades (2):120-131. 


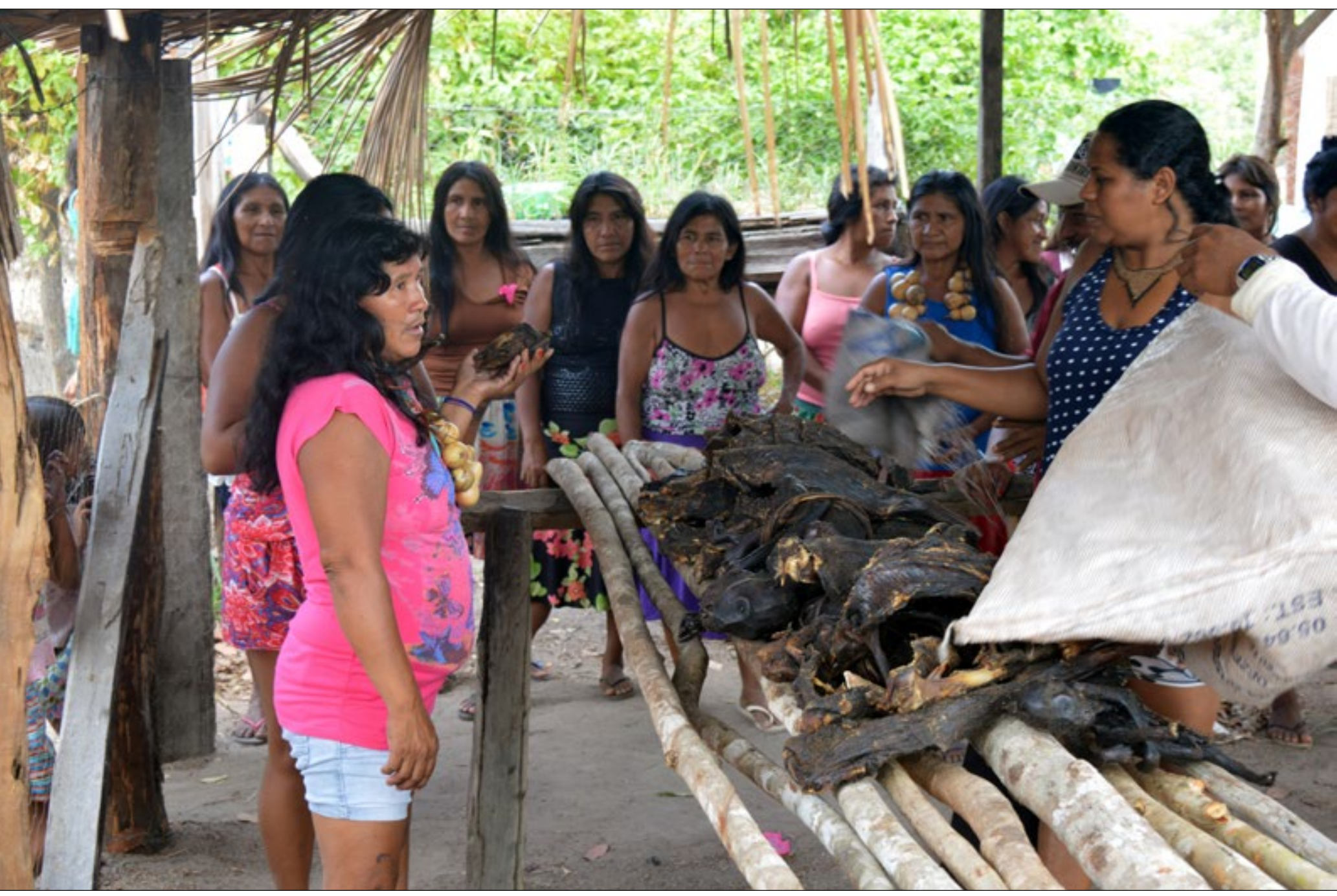

Figura 1 - Distribuição da carne de caça moqueada no jirau, para ser consumida durante a festa. Aldeia Lagoa Quieta, TI Arariboia, Maranhão. Foto: Ana Caroline Amorim Oliveira (2016). 


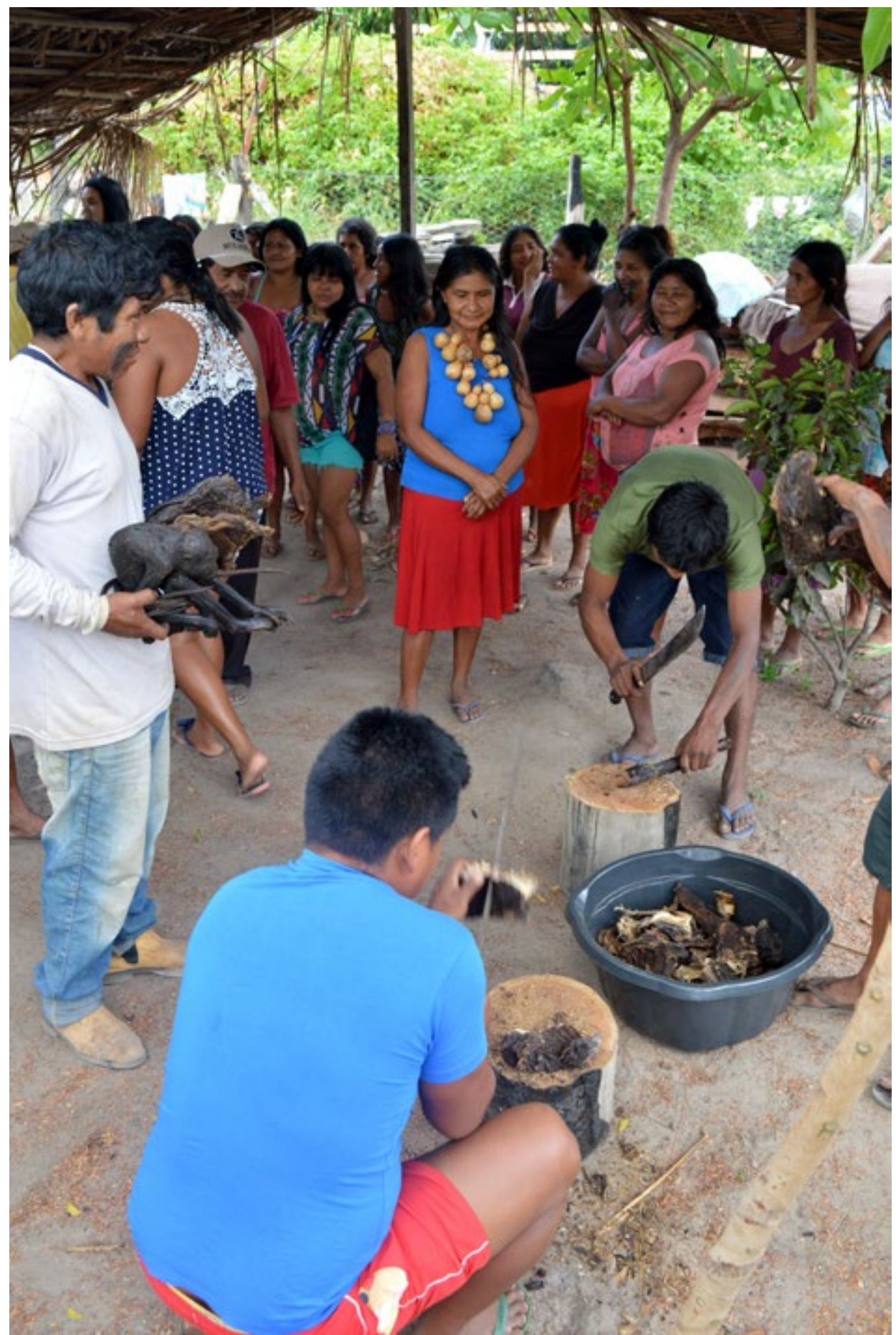

Figura 2 - Os caçadores dividem a carne de caça moqueada nas panelas, que será cozida sob os olhos atentos das mulheres. Aldeia Lagoa Quieta, TI Arariboia, Maranhão. Foto: Ana Caroline Amorim Oliveira (2016). 


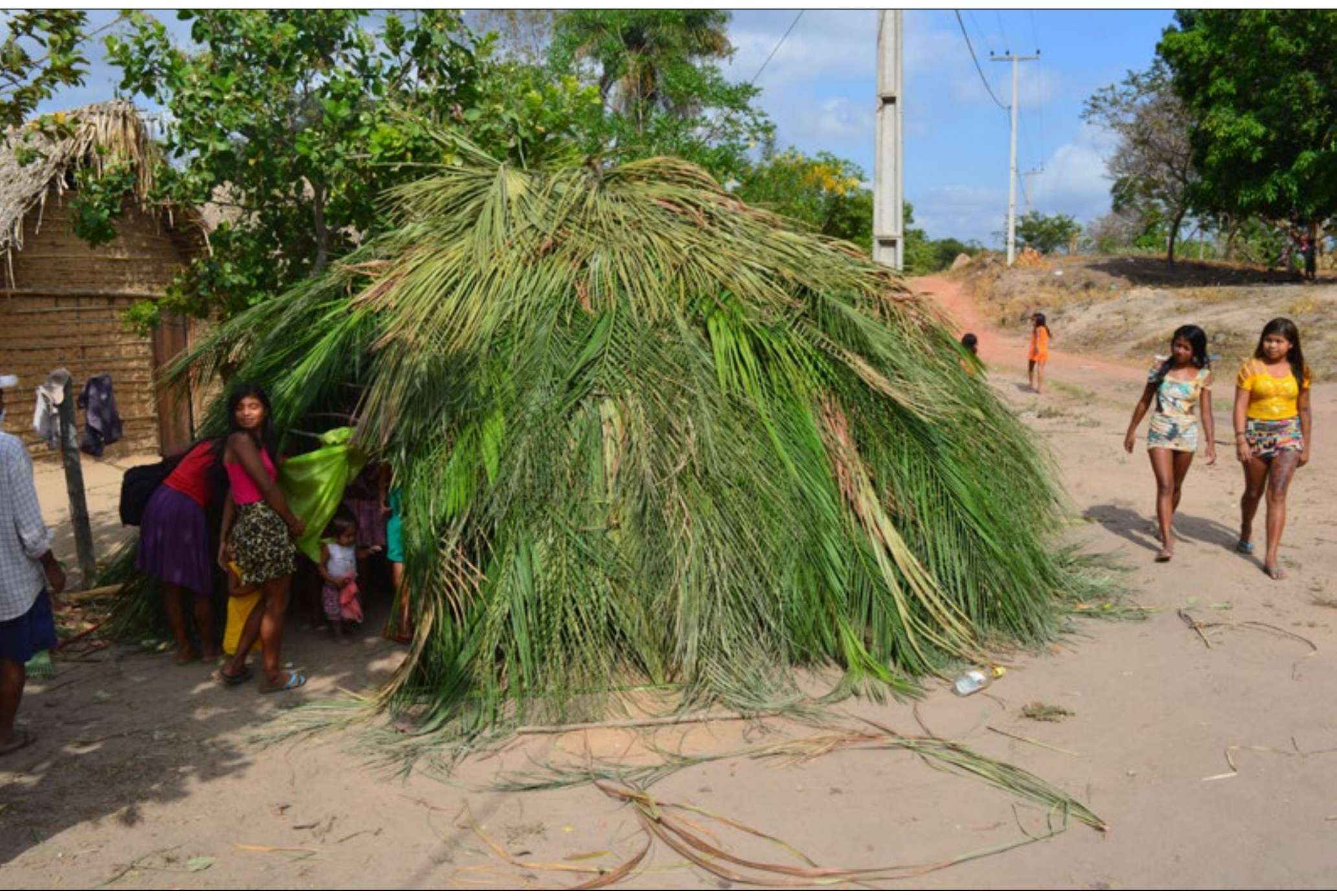

Figura 3 - Tocaia onde ficam recolhidas as meninas-moças para a festa. Apenas as mulheres podem entrar na tocaia. Aldeia Lagoa Quieta, TI Arariboia, Maranhão. Foto: Ana Caroline Amorim Oliveira (2016). 


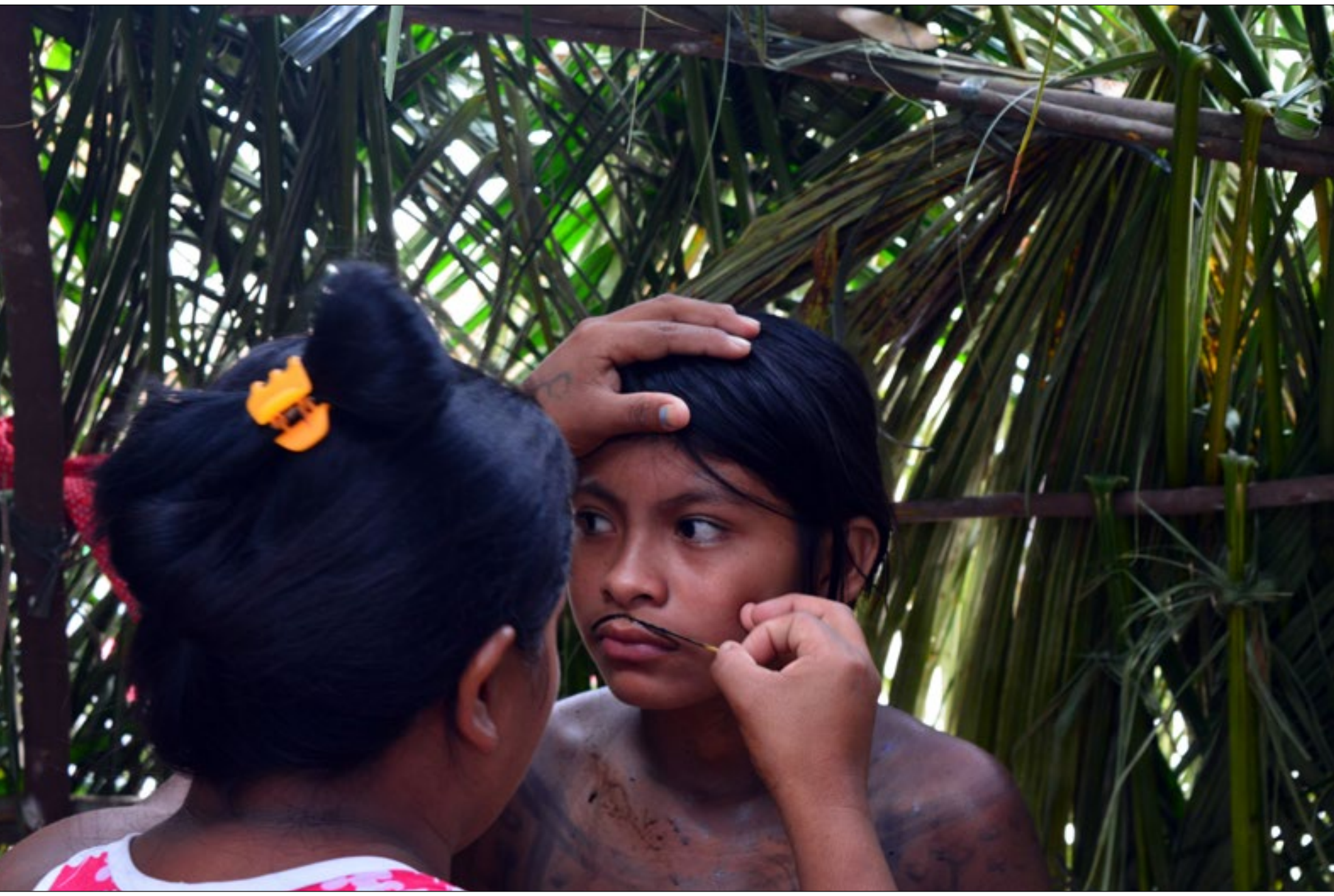

Figura 4 - Menina-moça sendo pintada de jenipapo pela mãe na tocaia. Aldeia Lagoa Quieta, TI Arariboia, Maranhão. Foto: Ana Caroline Amorim Oliveira (2016). 


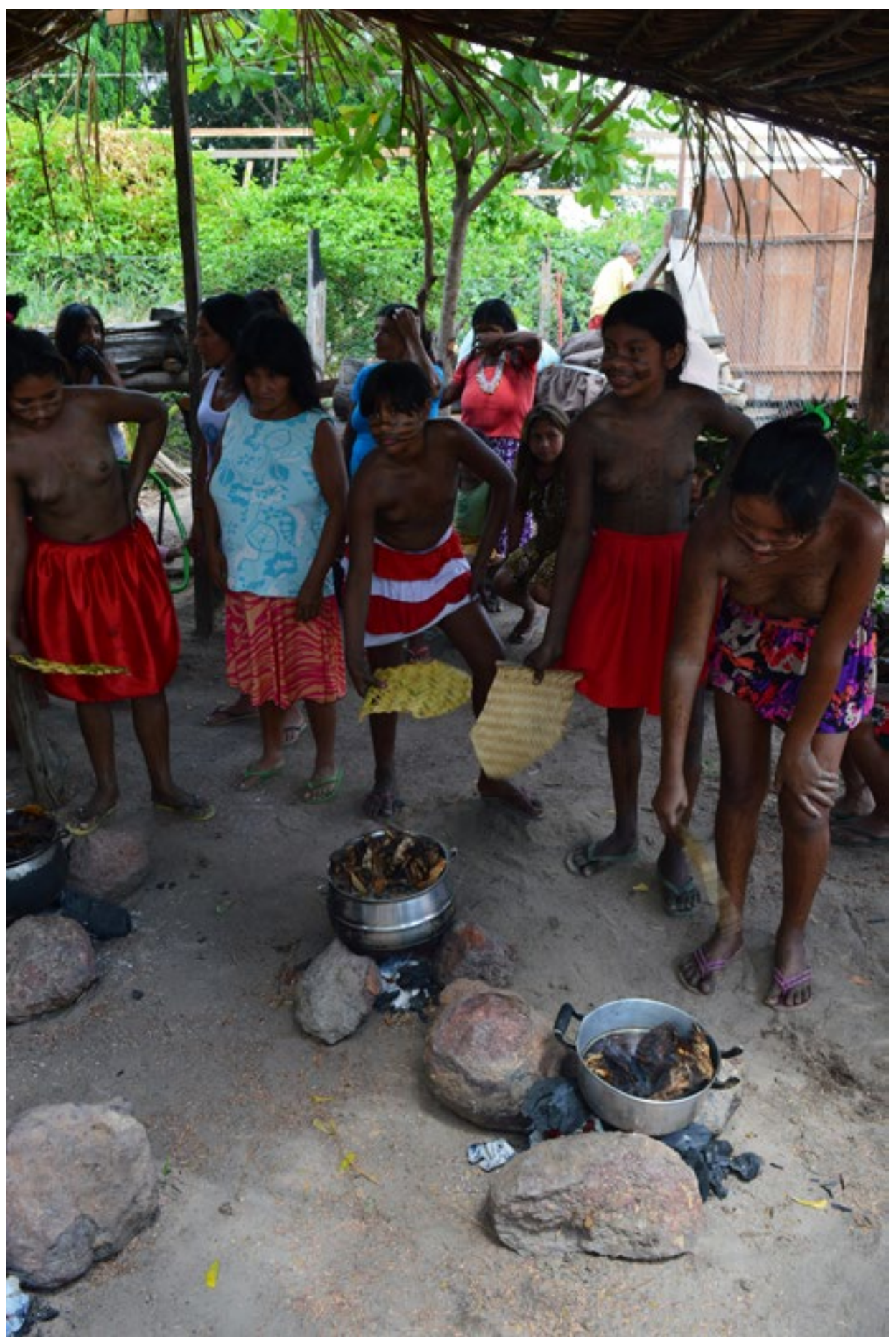

Figura 5 - Meninas-moças sendo observadas e ensinadas pelas mulheres mais velhas da comunidade sobre como preparar a carne de caça moqueada. É o momento de ensinamento sobre como ser uma mulher Tenetehara, com orientações dadas pelas mais velhas às mais novas. Aldeia Lagoa Quieta, TI Arariboia, Maranhão. Foto: Ana Caroline Amorim Oliveira (2016). 


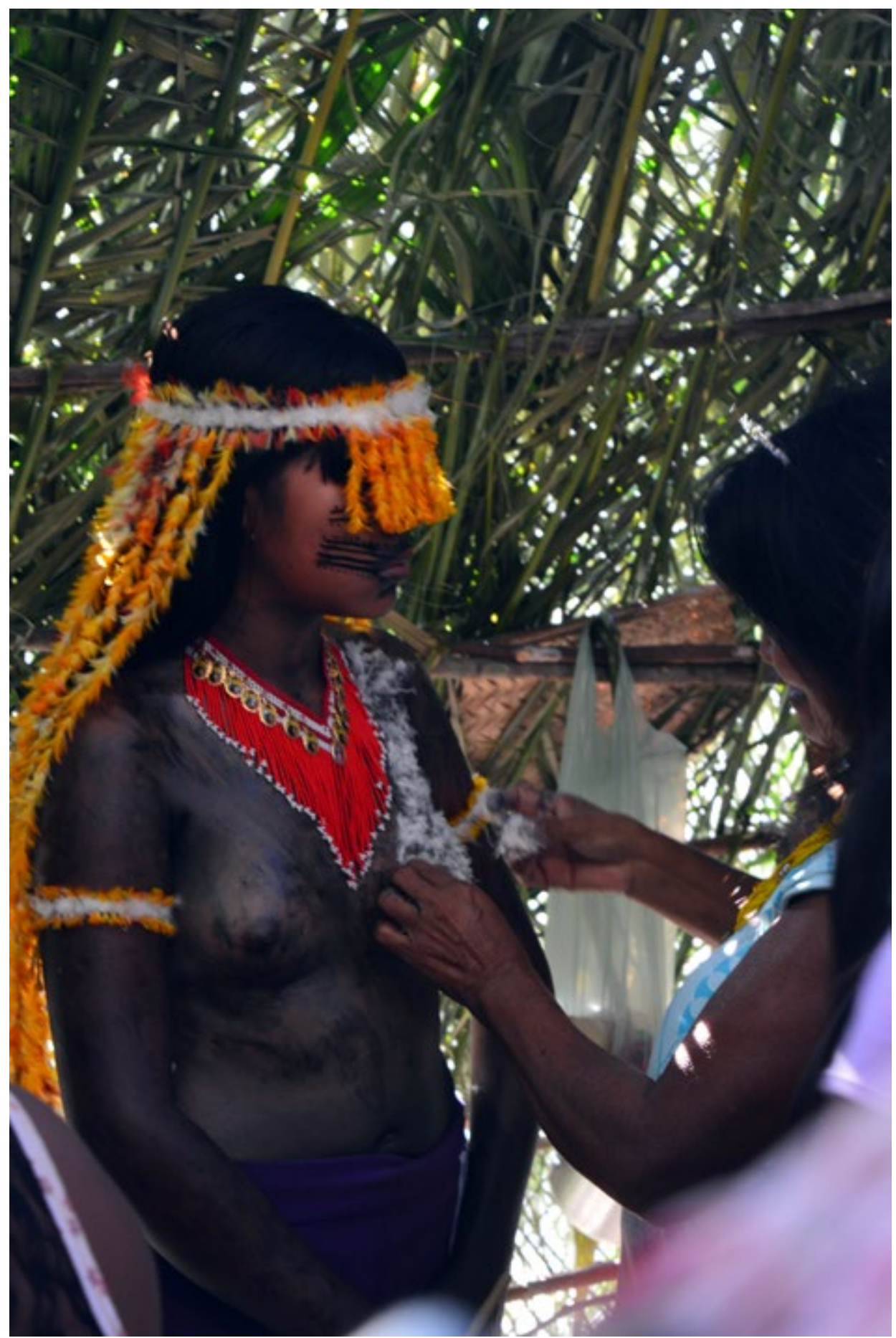

Figura 6 - Menina-moça sendo enfeitada pela mãe com Wýra'ý de penas amarelas e penas de gavião para a cantoria do final da tarde. Aldeia Lagoa Quieta, TI Arariboia, Maranhão. Foto: Ana Caroline Amorim Oliveira (2016). 


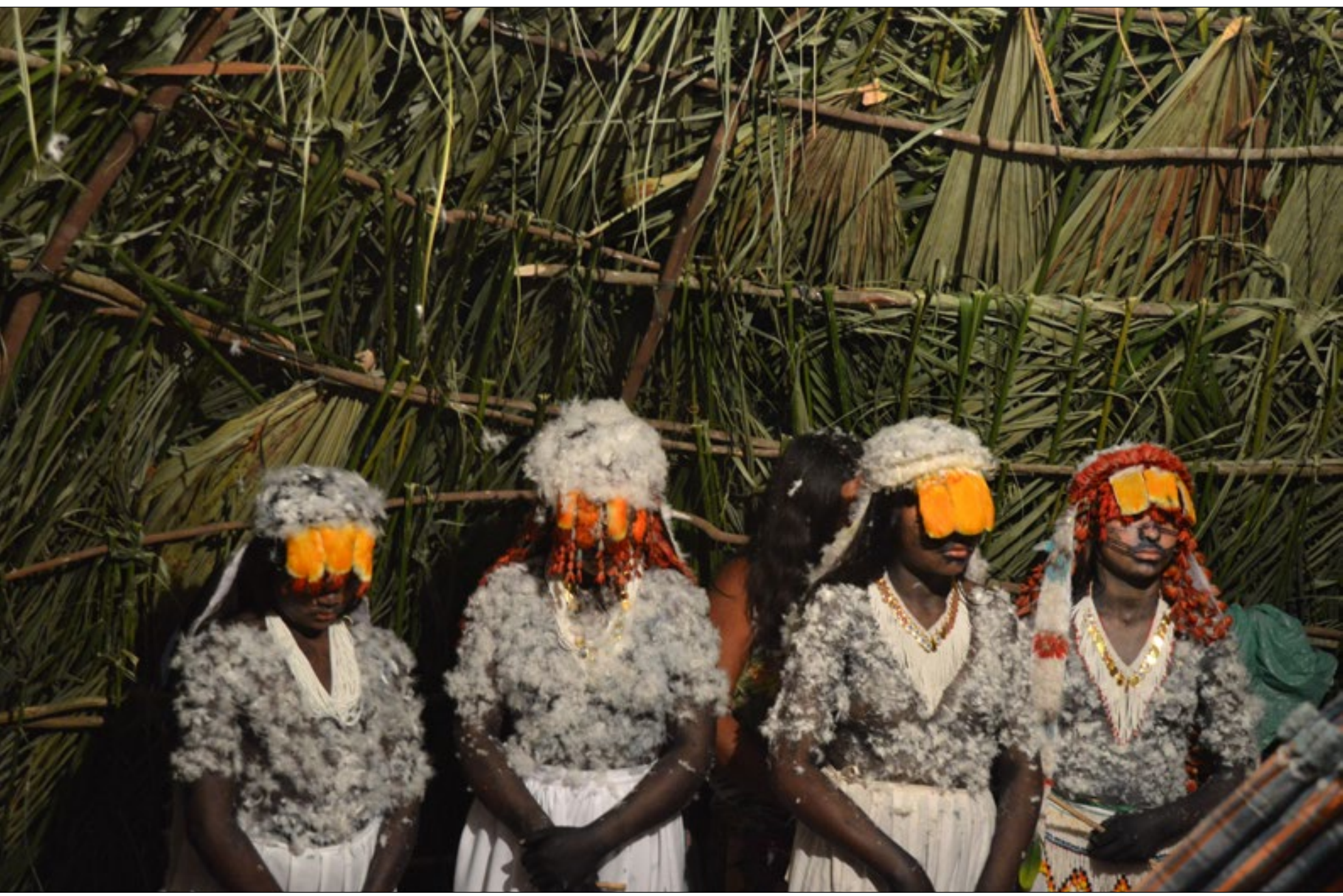

Figura 7 - Meninas-moças enfeitadas para presenciarem a saída antes do amanhecer, na tocaia, onde ocorre a última cantoria da festa. Aldeia Lagoa Quieta, TI Arariboia, Maranhão. Foto: Ana Caroline Amorim Oliveira (2016). 


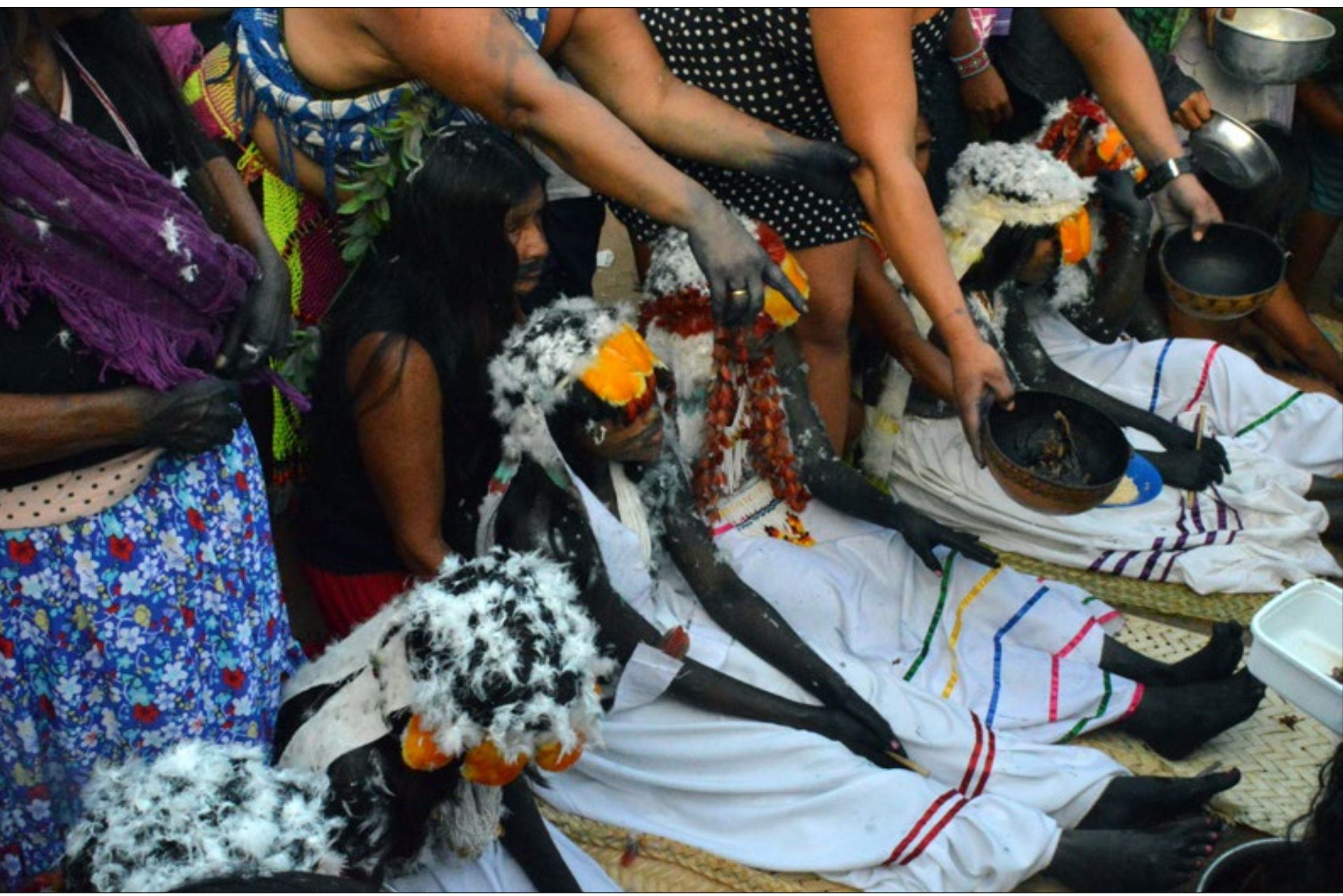

Figura 8 - Encerramento da festa, com distribuição dos bolinhos de carne de caça moqueada pelas meninas-moças, agora mulheres Tenetehara. Aldeia Lagoa Quieta, TI Arariboia, Maranhão. Foto: Ana Caroline Amorim Oliveira (2016). 